Article

\title{
Investigation of the Mechanical Properties of Vinylester-Based Sheet Moulding Compound (SMC) Subject to Particle Recycling
}

\author{
Vera Austermann *, Jonas Neuhaus, Daniel Schneider, Rainer Dahlmann (D) and Christian Hopmann
}

check for updates

Citation: Austermann, V.; Neuhaus, J.; Schneider, D.; Dahlmann, R.; Hopmann, C. Investigation of the Mechanical Properties of Vinylester-Based Sheet Moulding Compound (SMC) Subject to Particle Recycling. J. Compos. Sci. 2022, 6, 84 https://doi.org/10.3390/jcs6030084

Academic Editor: Abhishek

Kumar Pathak

Received: 27 January 2022

Accepted: 28 February 2022

Published: 8 March 2022

Publisher's Note: MDPI stays neutral with regard to jurisdictional claims in published maps and institutional affiliations.

Copyright: (C) 2022 by the authors. Licensee MDPI, Basel, Switzerland. This article is an open access article distributed under the terms and conditions of the Creative Commons Attribution (CC BY) license (https:// creativecommons.org/licenses/by/ $4.0 /)$
Institute for Plastics Processing (IKV), Faculty of Mechanical Engineering, RWTH Aachen University, 52074 Aachen, Germany; jonas.neuhaus@ikv.rwth-aachen.de (J.N.); daniel.schneider@ikv.rwth-aachen.de (D.S.); rainer.dahlmann@ikv.rwth-aachen.de (R.D.); zentrale@ikv.rwth-aachen.de (C.H.)

* Correspondence: vera.austermann@ikv.rwth-aachen.de

\begin{abstract}
In light of climate change, fiber-reinforced plastics (FRP) are becoming increasingly important due to their lightweight construction potential. This benefit is additionally expanded on with the low cycle times, scrap rates and material costs of Sheet Moulding Compounds (SMC), making it the most often used material on the FRP market. While extensive studies regarding the recycling of SMC with unsaturated polyester-based matrices (UP-SMC) have been conducted in the past, this is not the case for vinylester-based SMC (VE-SMC). In this research, VE-SMC components were subject to a particle-recycling approach. Recyclate in the form of VE-SMC regrind was used to substitute SMC matrices during the compounding process. The dependence of the mechanical properties and failure behavior of VE-SMC containing regrind was investigated by means of microscopic and mechanical test methods for varying mass proportions of SMC regrind. Due to the addition of SMC regrind, a decreased fiber/matrix adhesion was observed. Furthermore, an increase in pore formation was observed with an increasing proportion of SMC regrind. The flexural modulus increased by $20 \%$ with a low percentage of regrind $\left(\omega_{\mathrm{rSMC}}=10 \mathrm{wt} . \%\right)$ in comparison to virgin SMC. In contrast, the tensile properties decrease (up to 30\%) with the addition of SMC regrind independent of the investigated proportions of SMC regrind.
\end{abstract}

Keywords: mechanical recycling; sheet moulding compound; compression moulding; material cycle; regrind content

\section{Introduction}

Due to their lightweight construction potential and durability, fiber-reinforced plastics (FRP) are finding ever-wider applications, ranging from the transport sector to the construction and electronical sector [1]. The FRP market is extremely agile and has growing continuously by $5-10 \%$ year-over-year [2]. Compared with non-reinforced materials, FRPs enable a higher degree of weight-optimization and functional component design potential, and are therefore increasingly used to reduce fuel consumption and emissions $[3,4]$.

The material classes of Sheet Molding Compounds (SMC) and Bulk Molding Compounds (BMC, which is similar in composition to SMCs but usually have a lower fiber volume fraction $\left(\mathrm{v}_{\mathrm{F}}\right)$ ) are the largest market segment in the FRP industry, accounting for around a quarter of the volume processed. These semi-finished products can be processed in large production volumes and low cycle times using compression moulding (SMC/BMC) or injection moulding (BMC) methods. The total production volume in 2019 in Europe alone accounted for 287 kilotons [1].

However, so far, there is a lack of established closed-loop material cycles for the recovery and subsequent recycling of these materials. The increasing industrial and societal relevance of resource efficiency with regard to climate change, which has been emerging for years, increases the demand for FRP recycling strategies. Due to the inadequate separability of fiber and matrix as well as fillers and additives, FRP components can only be recycled at great expense [5]. 
The focus of previous research projects on the recycling of non-SMC FRP with thermoset matrix is on thermal recycling (e.g., pyrolysis) and chemical recycling (e.g., solvolysis). In both processes, the plastic matrix is decomposed or broken down by a hydrolysis reaction or alcoholysis reaction, so that only the fibers can be recovered $[6,7]$. These processes are very energy-intensive and, due to their low economic efficiency, are currently mainly used for recycling FRP with cost-intensive carbon fiber reinforcement [8]. Glassfiberreinforced plastics (GFRP), which account for over $95 \%$ of the international FRP market, are therefore not recycled in these processes [1].

GFRP, such as SMC, are often recycled mechanically. The composite is broken down by mechanical processes so that particle and fiber fractions are reclaimed for the reapplication of the material [5]. In contrast to thermal and chemical recycling processes, mechanical recycling is inexpensive, less energy-intensive and does not require the use of environmentally harmful substances. However, the fiber matrix bond cannot be completely removed during mechanical recycling, so the material bond remains intact $[7,9]$.

During mechanical recycling, SMC components are ground by means of size-reduction processes such as hammer or cutting mills. The fractions of different sizes, such as resinrich powder and fibers of different lengths still embedded in the resin, can be separated through a sieve. The mechanical treatment shortens the fibers and reduces their mechanical properties. The regrind is used, for example, in the SMC and BMC industry as a substitute filler instead of naturally occurring calcium carbonate. In some cases, component weights can be reduced through lower densities of the recyclate $[5,10,11]$. The fiber-containing particles can be re-used as reinforcing material. However, the mechanical properties are hardly increased compared to ordinary reinforcing fibers because of the poor adhesion of the recycled fibers to the matrix. The weight proportion of recycled fillers in the FRP is limited as this has a great influence on further processing. Besides SMC viscosity, mechanical properties are also strongly influenced. Therefore, the weight percentage of recycled filler is an unclear variable [5,12].

There are different resin systems available for manufacturing composites. Recently, FERDOUS ET AL. discussed mechanical properties of polyester- and vinylester-based compound in the literature. Their results show that the resin system plays a great role in fatigue-failure mode. Vinylester-based resin systems create a rigid bond with fibers resulting in GFRP laminates more prone to stress concentration under cyclic loading [13].

Furthermore, a varied amount (between $30 \%$ and $50 \%$ of the weight of resin) of ceram in the phenolic-based matrix to improve fire resistancy was investigated by FERDOUS ET AL. The results show the addition of ceram up to $50 \%$ ceram by weight of the resin resulted in only a $15 \%$ and $25 \%$ reduction in tensile strength in the longitudinal and transverse direction, respectively. Furthermore, the addition of $50 \%$ ceram powder improved the bending modulus by $37 \%$. However, this led to the composite laminates failing prematurely due to delamination [14].

Several investigations regarding the recycling of FRPs, especially focusing on the reuse of SMC with unsaturated polyester-based matrices (UP-SMC) regrind as substitute for filler material in new SMC structures, were carried out in the $1990 \mathrm{~s}$ [15-22], whereas in the following two decades, further research was promoted to a noticeably lesser extent. In Germany, the company ERCOM Composite Recycling GmbH-Kunststoffaufbereitung, Rastatt, carried out mechanical recycling of SMC at the beginning of the 1990s. Since it was not profitable in the long term, ERCOM had to close down due to insolvency [23].

The size and chemical composition of filler materials may influence fiber-matrix adhesion and matrix-failure initialization in SMC [24-26]. A deep understanding of the resulting mechanical properties is therefore essential in ensuring the reliable application of recycled SMC. PALMER ET AL. evaluated the resulting mechanical properties in particle recycling of UP-SMC, showing that the interface of the fresh matrix with the recycled matrix is not a weak point. Mechanical failure under stress is observed in the virgin matrix fraction of the SMC [27]. Adding the larger fiber-containing particles proves to be more complicated and a reduction in strength can be expected. The reason is assumed to be poor adhesion of 
the SMC regrind to the polymer matrix. By subsequent treatment of the particle surface, better adhesion can be achieved and the reduction of the mechanical properties can be minimized [5].

SMC regrind exhibits a higher adsorption ratio of the resin compared to the conventionally used filler calcium carbonate. Consequently, the processing viscosity increases, which may limit fiber wetting. Since the density of SMC regrind is lower than that of calcium carbonate, the component weight decreases by $5 \%$ when applying a weight percentage of SMC regrind of $\omega_{\mathrm{rSMC}}=10 \mathrm{wt} . \%\left(\mathrm{~kg}_{\mathrm{reg}} / \mathrm{kg}_{\mathrm{SMC}} 100\right)$ [5]. It has also been shown that an extended mixing process of the SMC resin with the SMC regrind has a positive effect on the mechanical properties. This is explained by a better homogenization and wetting of the recyclate with the virgin resin [12].

Vinylester resins are used for SMC components that require higher physical and mechanical properties, for example, for structural applications [28]. They are characterized by good thermomechanical properties while at the same time they exhibit high curing speeds and thus a high productivity. Their molecules are quite similar to UP molecules; however, a double bound is located in the terminal position of the chain $[29,30]$.

Past research focused on the re-use and application of regrinds from UP-SMC. However, fiber wetting behavior and resulting failure mechanisms in vinylester-based SMC (VE-SMC) differ, thus making it necessary to investigate the effects of the use of recyclates with VE SMC. Therefore, in this work, the influence of the weight proportions of recycled VE-SMC regrind on processing behavior and mechanical properties are investigated.

Furthermore, the practical investigation of this research is different to previous investigation, as the SMC regrind is applied to replace part of the resin instead of substituting the filler material. Substituting the resin instead of using recyclates as filler material facilitates a further increase in the sustainability of the recycled components.

Within the scope of this work, the question of how much by SMC recyclate can be used to substitute resin in the production of SMC components without causing significantly negative effects on the mechanical properties is to be answered. In order to test the influence of the recyclate on mechanical properties, SMC components with increasing recyclate content between 10 and 30 weight percent (wt.\%) of the resin are investigated.

For the investigations of this research, SMC components with SMC regrind weight percentages of $\omega_{\mathrm{rSMC}}=0 \mathrm{wt} \%$ (reference); $10 \mathrm{wt} \% ; 20 \mathrm{wt} \% ; 30 \mathrm{wt} . \%$ are characterized in order to detect the effects of an increasing proportion of recyclate. The SMC regrind as well as components with varied mass-weight percentages of SMC regrind are analyzed microscopically. Furthermore, the respective SMC components are comparatively analyzed in regard to the tensile and bending properties.

\section{Materials and Methods}

\subsection{Materials}

The terms depicted in Table 1 are defined to ensure a distinct material identification within this work.

Table 1. Definition of materials within this work for distinct material identification.

\begin{tabular}{cc}
\hline Material & Definition \\
\hline SMC regrind & ground VE-SMC material (recyclate) \\
SMC resin & mixture of resin, additives and (varied mass percentages of) SMC regrind \\
SMC preform & glass fibers impregnated with SMC resin \\
SMC components & compression moulded SMC \\
\hline
\end{tabular}

For the practical investigations of this work, SMC components were manually manufactured by hand lay up on a laboratory scale. In order to ensure the comparability of manually manufactured SMC materials of this research, the formulation of the SMC resin was adopted from a glassfiber-reinforced VE-SMC with a fiber weight proportion of 50 wt.\% by BYK Chemie GmbH, Wesel (Germany). The SMC components that were 
shredded and re-used as SMC regrind were also manufactured form the same BYK material. The components of the SMC resin in parts per hundred resin are shown in Table 2.

Table 2. Base composition of vinylester-based Sheet Moulding Compounds (VE-SMC) matrix.

\begin{tabular}{ccc}
\hline Component & Trade Name & Parts Per Hundred Resin \\
\hline Vinylester (VE) resin & Reichhold Dion 31056 & 92.5 \\
Low profile additive (Solution of a saturated polyester in styrene & Reichhold Norpol 9892 & 7.5 \\
for shrinkage compensation) & BYK BYK-P 9085 & 5 \\
Processing additive & BYK BYK-9076 & 3 \\
Wetting agent & Nouryon Trigonox 117 & 1.5 \\
Curing agent (tert.-Butylperoxy-2-ethylhexylcarbonat) & Axalta Coathylene HA 1681 & 2.5 \\
Dispersing/anti-shrinkage agent (Polyethylen (PE) powder) & Luvatol EK 100 KM & 8 \\
Thickener (magnesium oxide (MgO) paste) & \\
\hline
\end{tabular}

The SMC resin consists of several components. The basic resin of the matrix is the vinylester resin which is characterized by improved mechanical properties and chemical resistance. For shrinkage compensation, a low profile additive was used. This solution of saturated polyester (PES) in styrene, which is easily thickened by magnesium oxide, can provide a high filler charge and good surface quality. For additional dispersion enhancement and shrinkage compensation, a thermoplastic polyethylene (PE) powder was used. Peroxides that decompose at temperatures between $100-130^{\circ} \mathrm{C}$ and serve as polymerization initiators were used as curing agents. In addition, a magnesium oxide $(\mathrm{MgO})$ paste was used to thicken the resin. Furthermore, two process additives from the manufacturer BYK Chemie GmbH, Wesel (Germany) were used. The processing additive BYK-P 9085 improves the flow behavior and stabilizes the compound. It also has good release properties in the mold. Furthermore, the wetting and dispersing additive BYK 9076 was used for improved fiber wetting. This additive also prevents phase separation of thermosetting resin and the thermoplastic additive. The SMC resin has a high reactivity for rapid thickening and accumulates to a density of $1.6 \mathrm{~g} / \mathrm{cm}^{3}$.

A glass fiber (GF) roving was used as reinforcing fiber. The glass fibers are E-glass with a titer of 2400 tex. A thermoplastic hot-melt adhesive yarn with a titer of $167 \mathrm{dtex}$ was used to consolidate and fix the cut glass fibers. A styrene-proof polyamide (PA) film was used as the carrier film. The film is characterized by good tear resistance and prevents the evaporation of styrene during storage.

To improve the comparability of SMC characteristics of the SMC preform manufactured by BYK, a fiber weight proportion of $50 \mathrm{wt} . \%$ was desired for the manufacturing of the SMC preforms. However, preliminary tests have shown that sufficient distribution of the viscous resin on the glass fiber preform is not possible using the process described in Section 2.2, leading to poor impregnation of the fibers in particular along the preform edges, as shown in Figure 1. In order to ensure sufficient fiber impregnation, the fiber weight proportion of the SMC preforms for the comparative investigation was therefore reduced to $35 \mathrm{wt} . \%$. The resulting properties of the SMC material used in this study are listed in Table 3.
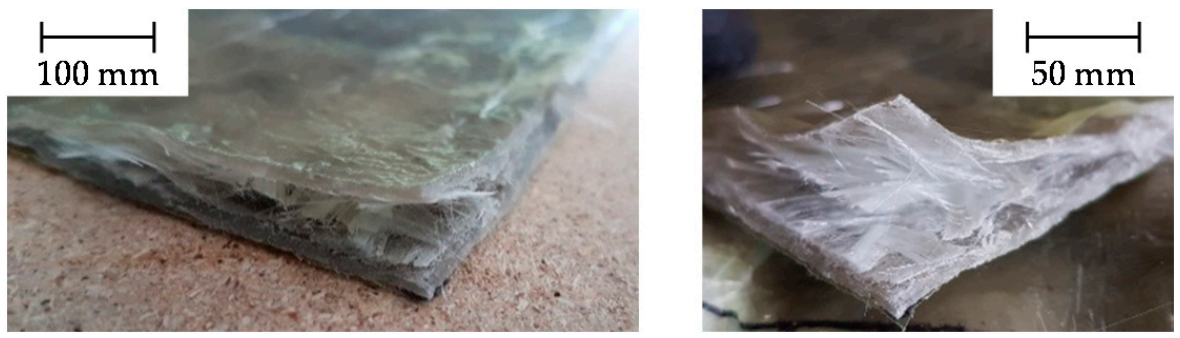

Figure 1. Inadequate fiber impregnation at the edges of the preform. 
Table 3. Properties of manually manufactured Sheet Moulding Compound (SMC) preforms.

\begin{tabular}{ccc}
\hline Material Properties & Unit & Value \\
\hline Density of SMC preform & $\mathrm{g} / \mathrm{cm}^{3}$ & 1.9 \\
Weight per unit area & $\mathrm{g} / \mathrm{m}^{2}$ & 3000 \\
Fiber weight proportion & $\%$ by weight & 35 \\
Fiber length & $\mathrm{mm}$ & 50 \\
SMC regrind share per formulation & \% by weight & $0 ; 10 ; 20 ; 30$ \\
\hline
\end{tabular}

\subsection{Manufacturing of SMC Components on a Laboratory Scale}

The manufacturing of the SMC components for the experimental investigations of this research can be subdivided into the six steps, as shown in Figure 2.

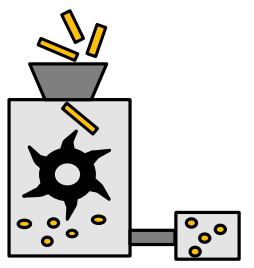

manufacturing of sheet mould compound (SMC) regrind

(1)

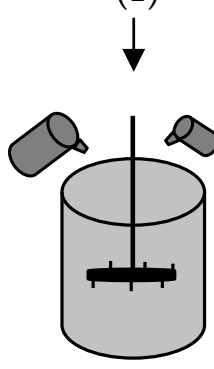

mixing of

SMC resin

(2)

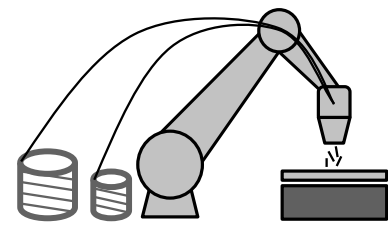

fiber spraying

(3)

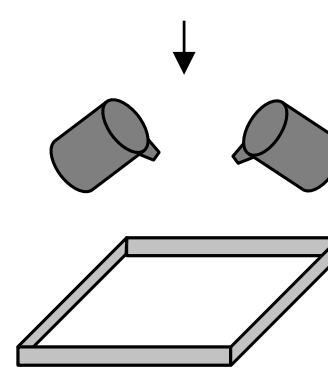

manufacturing of SMC preform

(4)

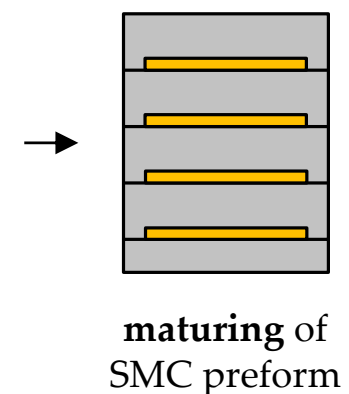

(5)

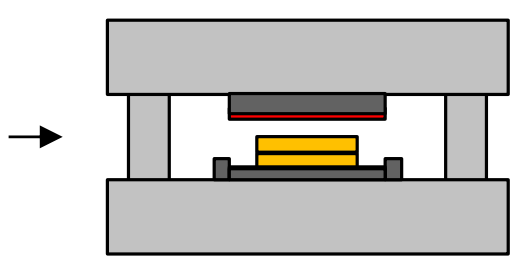

compression moulding of SMC components

(6)

Figure 2. Schematic illustration of manufacturing of SMC components on a laboratory scale.

First, in order to generate SMC regrind from compression moulded SMC components, the VE-SMC components were pre-crushed by means of a cutting mill from the manufacturer Rapid Granulator AB, Bredaryd (Sweden). The cutting unit mechanically crushes the SMC components. Since the crushed fractions have a particle size distribution, a perforated disc integrated in the mill was used to ensure a defined particle size. The pre-crushed material was further processed using a commercial mixer from the manufacturer Blendtec, Utah (USA), to facilitate further fragmentation. Finally, the ground material was sieved by a fine screen with a mesh width of $0.7 \mathrm{~mm}$. The particle size of the powder is therefore a maximum of $0.7 \mathrm{~mm}$ and is suitable for further processing as a substitution of resin in the manufacturing of the SMC preforms.

Second, the SMC resin was prepared with a varied proportion $\left(\omega_{\mathrm{rSMC}}=0 \mathrm{wt} . \%\right.$; $10 \mathrm{wt} . \% ; 20 \mathrm{wt} . \% ; 30 \mathrm{wt} . \%)$ of SMC regrind. The SMC regrind substitutes the VE resin proportionally, since a certain mixing ratio must be maintained and all the required proportions of the individual components are adjusted accordingly. Two different types of stirrers with a diameter of $60 \mathrm{~mm}$ were used to achieve an optimal homogenization of the resin 
paste. First, a three-bladed paddle stirrer was used to homogenize all liquid components. Second, a toothed dispersing disk was used in order to generate high shear forces. Thus, all solid components, such as the SMC regrind, can be homogeneously incorporated and dispersed into the paste without the occurrence of agglomerates [31]. The added recyclate caused the viscosity of the SMC resin to increase significantly by almost $40 \%$ (measured by plate plate rheometer following DIN EN ISO 3219). To ensure good manual distribution of the resin paste on the carrier film, a new SMC resin mixture was individually prepared for each preform. Before the SMC resin was further processed, the mixture was vented in a vacuum oven for $30 \mathrm{~min}$.

Third, the reinforcing fibers were prepared by a fiber spraying process. By means of this process, a semi-finished GF preform with random fiber orientation was manufactured $[32,33]$. Thus, the preforms manufactured with fiber spraying correspond very well to the reinforcing fibers in industrial SMC production. The GF roving as well as a thermoplastic binder yarn were fed to an integrated cutting unit, which cuts the fibers to a defined length of $50 \mathrm{~mm}$. A suction unit ensures a short-term fixation of the cut and loose fibers. A hot-air unit installed at the robot head melts the thermoplastic binder yearn and ensures the stability of the preform by bonding the binder with the GF. After a short cooling phase, the GF preform can easily be handled.

Fourth, the SMC preform was manually laid up. This process can be subdivided into four steps, depicted in Figure 3. The PA carrier foil was coated with the necessary amount of SMC resin (1). Then, the coated carrier foil was turned down and the bottom side of the glass fibers were impregnated with the resin (2) by means of venting rollers. The venting rollers also ensure that the preform is vented in order to minimize the formation of pores in the pressed SMC compounds. Subsequently, the impregnation was repeated for the top side of the preform ( 3 and 4 ). The impregnation from both sides was used to achieve a more uniform impregnation of the glass fibers.
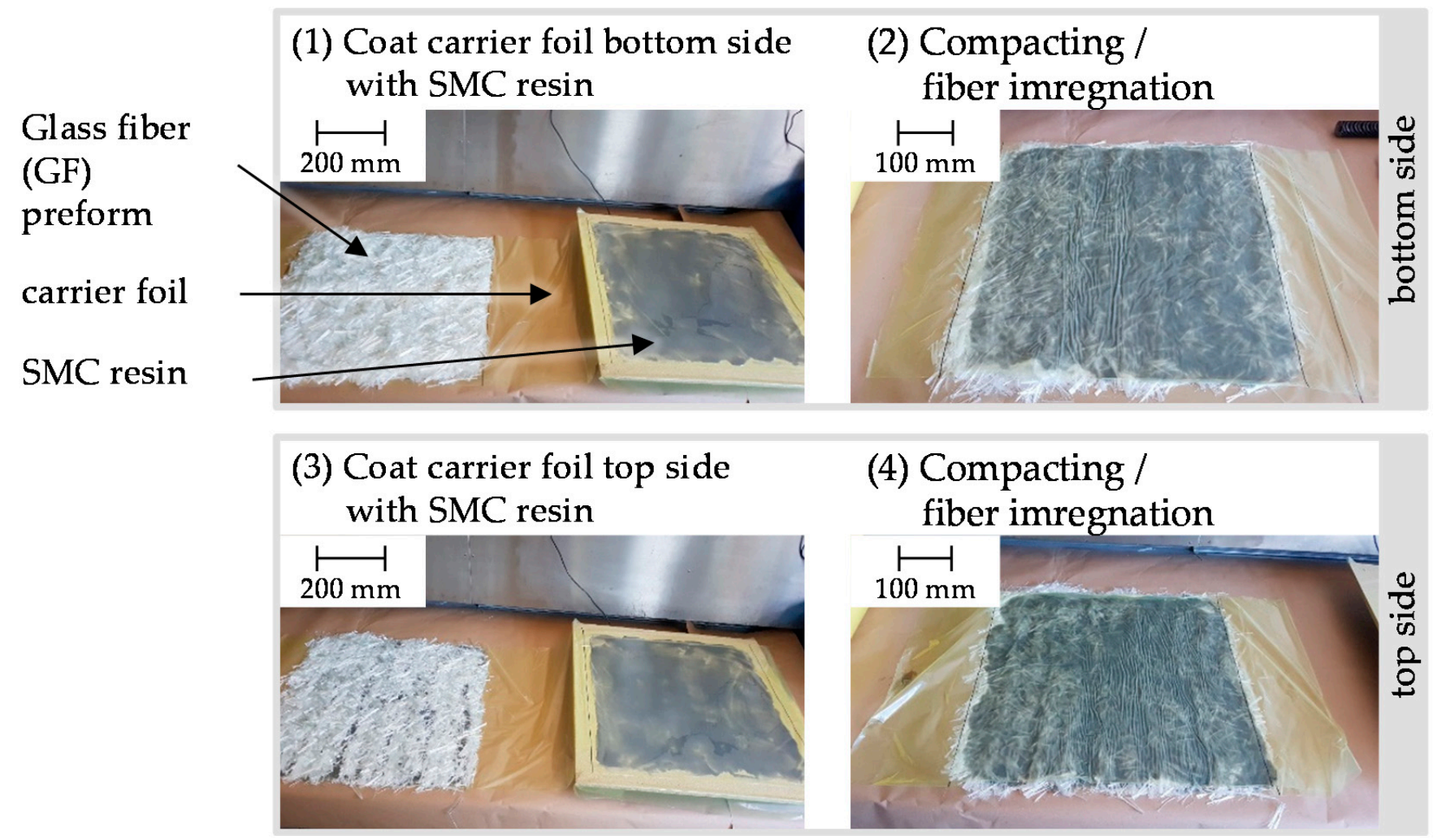

Figure 3. Exemplary manufacturing of SMC Preform with SMC regrind content of $\omega_{\mathrm{rSMC}}=20 \mathrm{wt} . \%$ by manual layout and compaction. 
Fifth, the SMC preforms were stored for $17 \mathrm{~h}$ at $30^{\circ} \mathrm{C}$ and subsequently for $72 \mathrm{~h}$ at room temperature for maturing. The material was matured to increase the viscosity to 20,000-150,000 Pa.s, which is the required viscosity for ensuring sufficient fiber flow during processing [34]. For this purpose, the SMC preforms were shrink-wrapped in styrene-proof foil and initially stored at $30^{\circ} \mathrm{C}$ for $17 \mathrm{~h}$ and subsequently stored at room temperature for a further $72 \mathrm{~h}$ in an autoclave at ambient pressure.

Sixth, the SMC components were compression moulded on an $1800 \mathrm{t}$ hydraulic composite press by Schuler AG, Göppingen (Germany) at Aachen Center for Integrative Lightweight Production (AZL), Aachen. The compression parameters are listed in Table 4. Before each pressing process, a release agent (Frekote 770 NC, Loctite, Düsseldorf (Germany)) was applied to the tool in order to allow easy demoulding of the SMC components. After the carrier foil was removed from the SMC preform, the preform was placed centrally on the pre-tempered tool to ensure an even flow. The outer dimensions of the SMC components are $695 \times 295 \times 4 \mathrm{~mm}^{3}$ and the edges of the component geometry prevented misalignment of the fibers alongside the edges. After demoulding, the SMC components are cooled for $24 \mathrm{~h}$ at room temperature. The SMC components for varied SMC regrind content are depicted in Figure 4. For each SMC regrind content investigated in this work, two SMC components were manufactured and experimentally investigated.

Table 4. Process parameters of compression moulding process.

\begin{tabular}{ccc}
\hline Process Parameters & Unit & Value \\
\hline Press force & $\mathrm{kN}$ & 2100 \\
Initial mold coverage & $\%$ & 50 \\
Position of SMC preform & - & centered \\
Pre-heating time & $\mathrm{s}$ & 45 \\
Curing time & $\mathrm{s}$ & 300 \\
Compression speed & $\mathrm{mm} / \mathrm{s}$ & 5 \\
Mold temperature (top/bottom) & ${ }^{\circ} \mathrm{C}$ & $150 / 135$
\end{tabular}

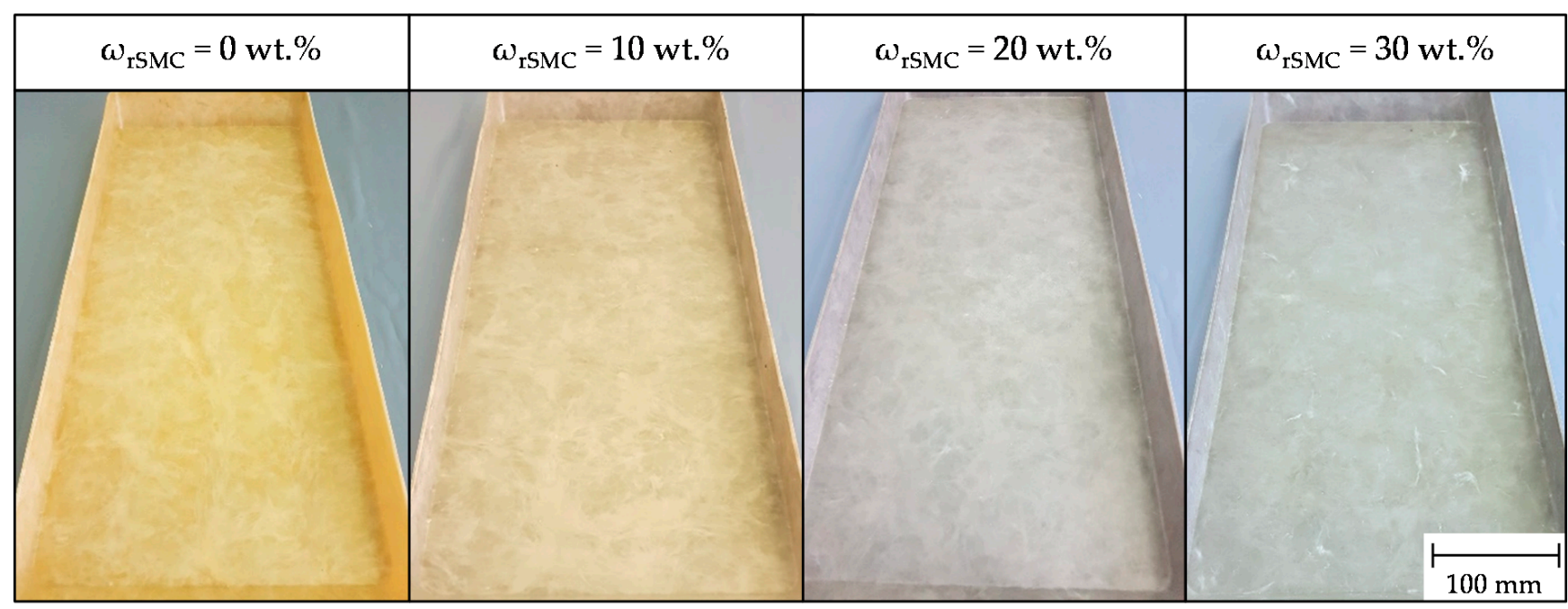

Figure 4. SMC components with varied SMC regrind content.

\subsection{Experimental Methods}

Figure 5 shows an overview of the experimental design further explained in the following. 


\begin{tabular}{|c|c|c|}
\hline Materials & $\begin{array}{c}\text { SMC regrind weight } \\
\text { percentage } \omega_{\text {rSMC }}\end{array}$ & $\begin{array}{l}\text { Experimental method } \\
\text { Aim of investigation }\end{array}$ \\
\hline SMC regrind & 100 wt. \% & $\begin{array}{l}\text { Light microscope examination } \\
\text { Structure and topography of SMC regrind }\end{array}$ \\
\hline \multirow{4}{*}{$\begin{array}{c}\text { SMC } \\
\text { components }\end{array}$} & & $\begin{array}{l}\text { Comparison of tensile properties with } \\
\text { conventional material } \\
\text { Validation of manual SMC manufacturing }\end{array}$ \\
\hline & 0 wt.\% & $\begin{array}{l}\text { Mechanical testing } \\
\text { Tensile properties } \\
\text { Bending properties }\end{array}$ \\
\hline & $\frac{10 \text { wt. } \%}{20 \text { wt } \%}$ & $\begin{array}{l}\text { Light microscope examination } \\
\text { Microstructure analysis }\end{array}$ \\
\hline & 30 wt.\% & $\begin{array}{l}\text { Scanning electron microscope } \\
\text { examination } \\
\text { fiber/matrix adhesion analysis }\end{array}$ \\
\hline
\end{tabular}

Figure 5. Overview of the experimental design.

\subsubsection{Microscopic Investigations}

Two digital light microscopes, VHX-600 and VHX-5000 from KEYENCE Deutschland $\mathrm{GmbH}$, Neu-Isenburg (Germany), were used for analysis of the SMC regrind as well as the SMC components. The SMC regrind was examined microscopically for a better assessment of structure and topography. The particle geometry allows conclusions to be drawn about impregnation quality and integration into the compound [31].

In order to analyze the material distribution of the composite, the microstructure of the SMC components was investigated by means of the VHX-5000 [35]. Three samples were randomly selected from each SMC component and embedded in a cold-curing epoxy resin. The removal positions of the samples were distributed over the whole component. After $24 \mathrm{~h}$ of curing, the specimens were sanded and polished with the sanding and polishing machines RoroPol21 by Struers GmbH, Willich (Germany), and Saphir 560 by ATM Qness GmbH, Mammelzen (Germany). The remaining impurities were removed in an ultrasonic bath.

The microsection of the SMC components allowed for a qualitative assessment of fiber/matrix adhesion [36]. Thus, for further investigation of the fiber/matrix impregnation, a scanning electron microscopic (SEM) was used to observe the fracture surfaces of the SMC components. Typically, images captured with a scanning electron microscope have a high depth of focus and thus allow the analysis the corresponding fiber/matrix adhesion, which has a decisive influence on the mechanical properties of SMC [36]. Therefore, three small rods were taken from each SMC components and notched after preparation. The specimens were then deep-frozen in liquid nitrogen and broken apart (cryogenic breakage). Prior to evaluation, the surface was made electrically conductive by the physical vapor deposition (sputtering) of a gold layer. The acceleration voltage used for the recordings $\mathrm{w}$ $2 \mathrm{kV}$.

\subsubsection{Mechanical Testing}

To characterize the mechanical properties of SMC components, tensile tests (DIN EN ISO 527-4) and four-point bending tests (DIN EN ISO 14125) were conducted. As SMC 
components exhibit flow-induced anisotropic areas alongside the edges due to the pressing process, an area of $10 \mathrm{~mm}$ was cut off on all sides [37]. For each investigated regrind content, three test plates were manufactured for the mechanical tests. Ten tensile specimens were extracted from each test plate. Due to the possibly anisotropic areas, five specimens were withdrawn in parallel and five specimens transverse to the direction of flow. Furthermore, five bending specimens were selected parallel to the direction of flow. All test specimens were removed by a water-cooled diamond circular saw according to the sawing plan depicted in Figure 6. The specimens were manufactured in accordance with DIN EN 13421, however, the mold coverage of $50 \%$ deviates from the $25-30 \%$ specified in the standard. The higher mold coverage was chosen in order to achieve a more homogeneous heating of the SMC preform after inserting into the heated mold.

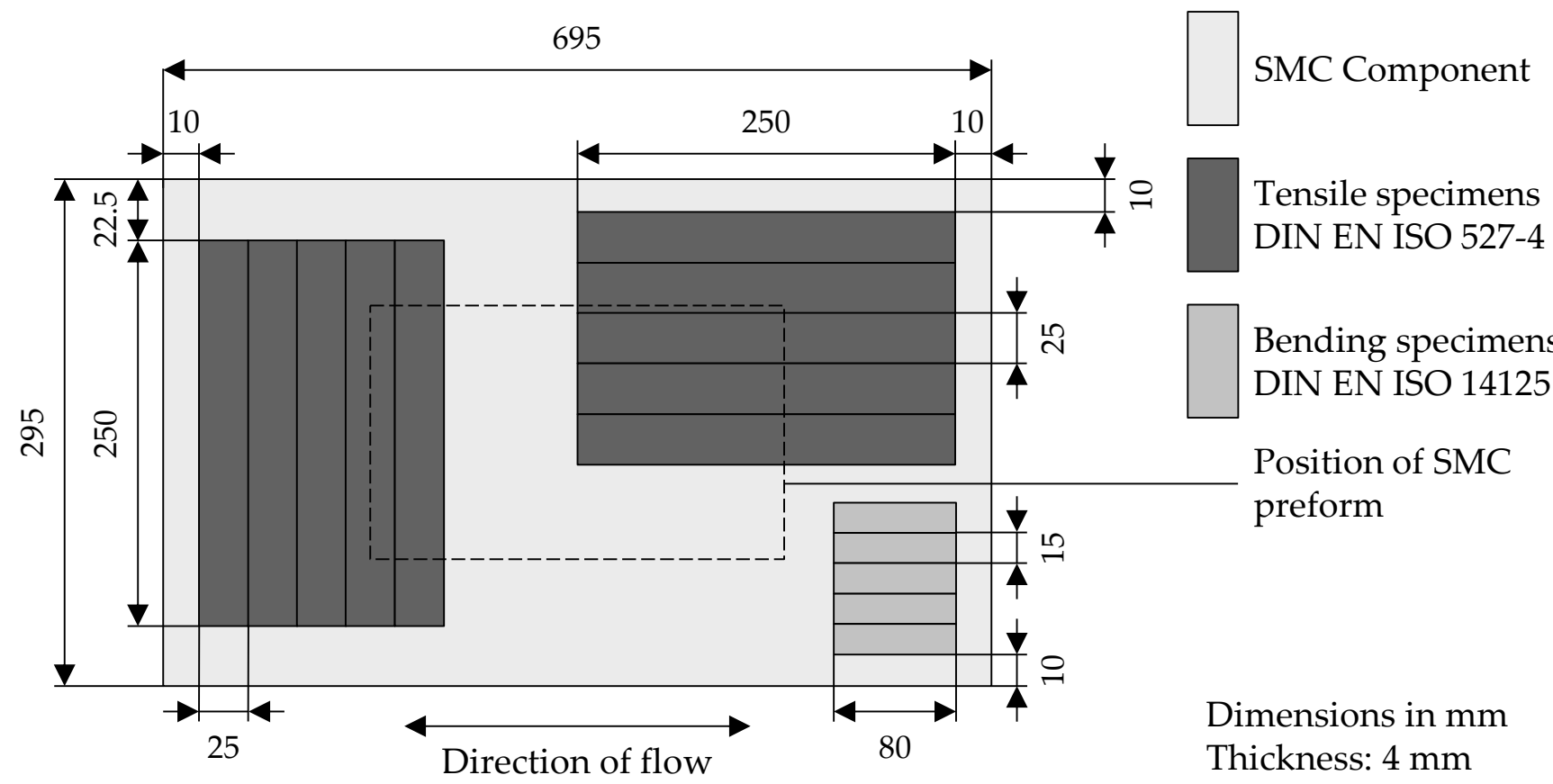

Figure 6. Sawing plan for the tensile and bending specimens of the SMC components.

Tensile Tests

The tensile tests were performed on a universal testing machine type Z150 from Zwick/Roell AG, Ulm (Germany), with a 150 kN load cell. Following DIN EN ISO 527-4, the test settings are listed in Table 5. The elastic modulus was determined in the strain range from $0.05-0.25 \%$. Contact extensometers were used to measure the strain during the test procedure. The tensile test specimens have the dimensions $250 \times 25 \times 4 \mathrm{~mm}^{3}$ and correspond to test specimen type 2 according to DIN EN ISO 527-4.

Table 5. Settings of Z150 for tensile testing.

\begin{tabular}{ccc}
\hline Settings & Unit & Value \\
\hline Load Cell & $\mathrm{kN}$ & 150 \\
Preload & $\mathrm{N}$ & 5 \\
Loading Rate & $\mathrm{mm} / \mathrm{min}$ & 2 \\
\hline
\end{tabular}

Four-Point Bending Tests

Four-point bending tests following DIN EN ISO 14125 were performed to determine bending stress and bending modulus. Compared to the three-point-bending test, a constant bending moment between the compression fins allows a larger and more homogeneous test range [38]. The testing machine used is a universal testing machine type Z100 from 
Zwick/Roell AG, Ulm (Germany), with a $100 \mathrm{kN}$ load cell, the test settings are listed in Table 6. The bending modulus was determined in the strain range of $0.05-0.25 \%$. The bending test specimens with the dimensions $80 \times 15 \times 4 \mathrm{~mm}^{3}$ correspond to test specimen type class II according to DIN EN ISO 14125.

Table 6. Settings of Z150 for four-point bending testing.

\begin{tabular}{ccc}
\hline Settings & Unit & Value \\
\hline Load Cell & $\mathrm{kN}$ & 100 \\
Preload & $\mathrm{N}$ & 2 \\
Loading Rate & $\mathrm{mm} / \mathrm{min}$ & 2 \\
Support span & $\mathrm{mm}$ & 66 \\
Loading span & $\mathrm{mm}$ & 22 \\
Radius of the compression fins & $\mathrm{mm}$ & 5 \\
\hline
\end{tabular}

\section{Results and Discussion}

\subsection{Validation of SMC Manufacturing on a Laboratory Scale}

Prior to analyzing the influence of SMC regrind content, the manual manufacturing of the SMC was verified. Thus, the mechanical properties of the SMC components with $\omega_{\mathrm{rSMC}}=0 \mathrm{wt} . \%$ recyclate content manually manufactured for this research are compared with the conventional SMC manufactured by BYK. The formulation of the BYK material is identical to the $\omega_{\mathrm{rSMC}}=0 \mathrm{wt} . \%$ formulation used in this work, with the difference that the BYK material fiber weight proportion is $50 \mathrm{wt} . \%$ instead of $35 \mathrm{wt} . \%$. The mechanical properties are compared in Table 7. Since all SMC preforms were produced under the same conditions and the properties were examined as a function of the proportion of recycled material, the findings of this work permit a valid comparative evaluation.

Table 7. Comparison of mechanical properties of conventional SMC and manually manufactured SMC determined using DIN EN ISO 527-4.

\begin{tabular}{cccc}
\hline Properties & Unit & $\begin{array}{c}\text { Conventional SMC } \\
\text { Fiber Weight Proportion 50 wt.\% }\end{array}$ & $\begin{array}{c}\text { Manually Manufactured SMC } \\
\text { Fiber Weight Proportion 35 wt.\% }\end{array}$ \\
\hline Tensile strength & {$[\mathrm{MPa}]$} & 134.5 & 75.1 \\
Elastic modulus & {$[\mathrm{GPa}]$} & 10.1 & 9.6 \\
\hline
\end{tabular}

\subsection{Microscopic Characteristics of the SMC Regrind}

In Figure 7, a structural overview of the SMC regrind at $100 \times$ magnification is depicted. It is noticeable that there is a large particle-size distribution. Subsequently, the regrind was divided into a fine and coarse fraction by sieving using a mesh width of $0.7 \mathrm{~mm}$.

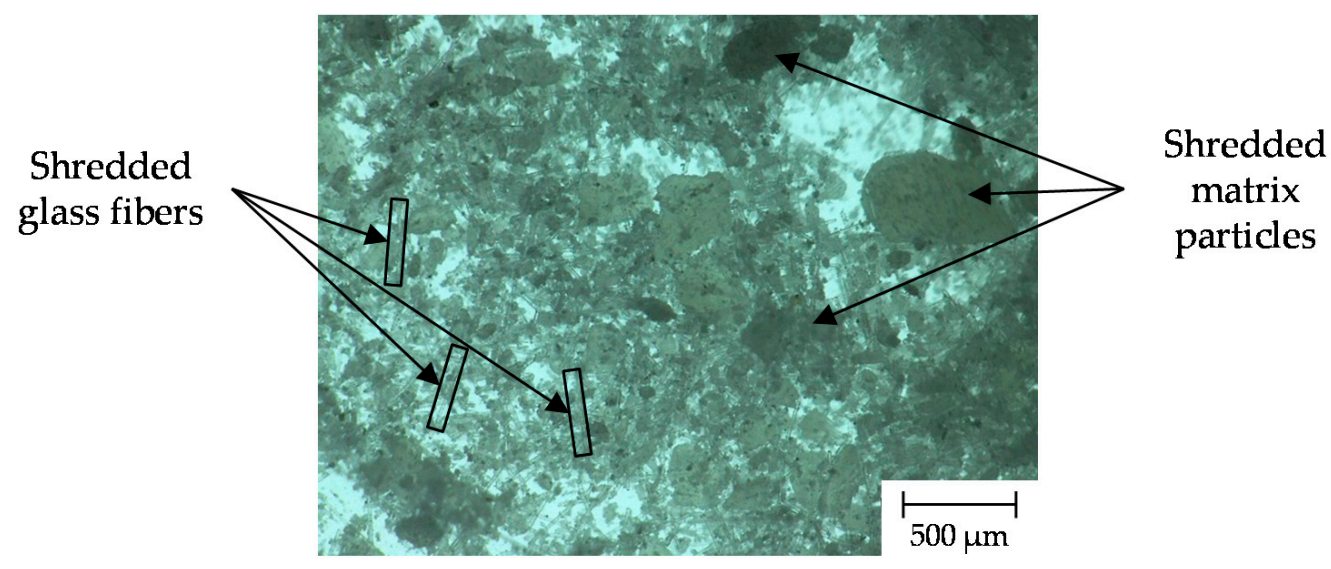

Figure 7. $100 \times$ magnification of the SMC regrind taken on VHX-600 digital microscope. 
For closer examination, the fine fraction was viewed at $400 \times$ magnification and the coarse fraction at $300 \times$ magnification, which is depicted in Figure 8 . The microscopic image of the fine fraction (left) shows that small matrix particles adhere to the fiber fragments. Furthermore, the fiber fragments differ significantly in length. Small loose matrix particles are also visible. The microscopic image of the coarse fraction (right) presents an example of a matrix-containing particle in which fibers are embedded. The assumption that the maximum particle size by using the fine sieve is $0.7 \mathrm{~mm}$ was confirmed by microscopic examination. The fine fraction therefore mainly consists of fibrous particles and small matrix particles, while the coarse fraction is dominated by matrix particles.
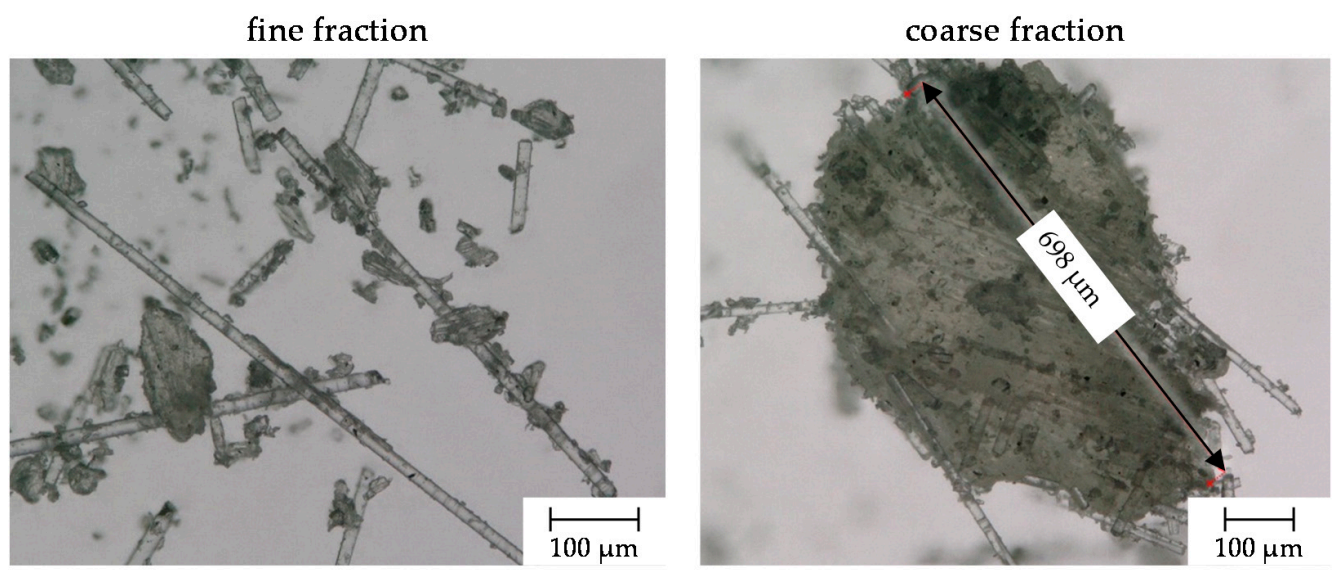

Figure 8. $400 \times$ magnification of the fine fraction and $300 \times$ magnification of coarse fraction of the $\mathrm{SMC}$ regrind taken on VHX-5000 digital microscope.

\subsection{Mechanical Properties of the SMC Components}

The ultimate tensile strength measured parallel and transverse to the direction of flow are depicted in Figure 9.

$\square$ parallel $\square$ transverse

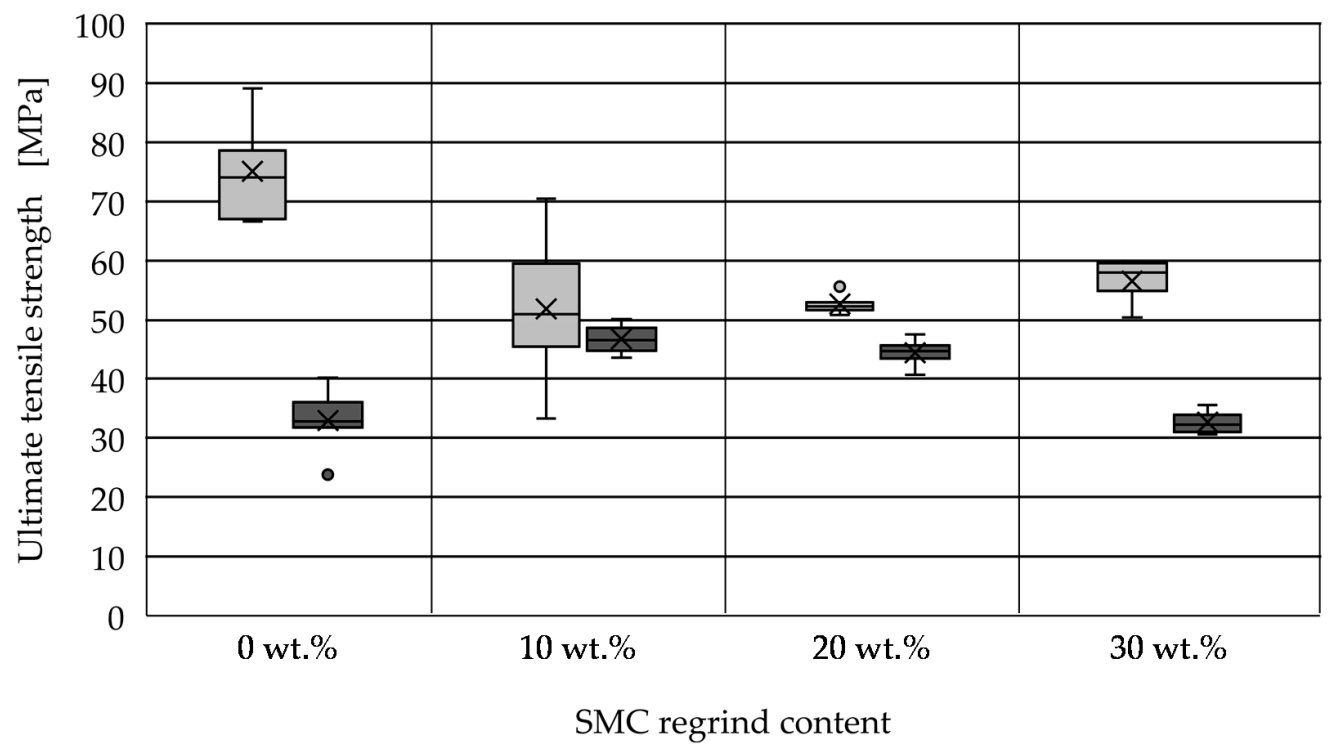

Figure 9. Ultimate tensile strength of SMC components with varied SMC regrind content.

The parameters differ when distinguishing between samples parallel and transverse to the direction of flow. Samples taken transversely to the flow direction achieve lower strength values than samples taken in parallel direction. In particular, the samples with $\omega_{\mathrm{rSMC}}=0 \mathrm{wt} . \%$ and $30 \mathrm{wt} . \%$ show significant differences in the achieved tensile strengths. 
This indicates that flow-induced anisotropic areas are present in the SMC components due to the pressing process.

It is noticeable that the scatter of the SMC components with $\omega_{\mathrm{rSMC}}=20 \mathrm{wt} . \%$ and $30 \mathrm{wt} . \%$ were significantly lower compared with $\omega_{\mathrm{rSMC}}=0 \mathrm{wt} . \%$ and $10 \mathrm{wt} . \%$. The high scattering of the measured values results from the heterogeneous structure of the SMC components and the locally varying glassfiber content [39]. This trend is further promoted due to the manual manufacturing of the SMC preforms.

Looking at the samples taken in parallel direction, the SMC components with $\omega_{\text {rSMC }}=0 \%$ shows the highest tensile strength values. A clear decrease in the tensile strength values is evident for all samples with regrind content. However, the characteristic values for the samples of the SMC components with $\omega_{\mathrm{rSMC}}=10 \mathrm{wt} \%, 20 \mathrm{wt} \%$ and $30 \mathrm{wt}$ \% do not differ significantly.

The characteristic values of the samples taken transversely show a different course. The highest tensile strength values were exhibited by the SMC components with $\omega_{\mathrm{rSMC}}=10 \mathrm{wt} . \%$ and $20 \mathrm{wt} . \%$, which achieved similar values. On the other hand, the tensile strengths of SMC components with $\omega_{\mathrm{rSMC}}=0 \mathrm{wt} . \%$ and $30 \mathrm{wt} . \%$ decreased to the same level.

It can be concluded that the properties of the cross direction are overall less influenced by the incorporation of SMC regrind. Due to the compression moulding process, the reinforcing fibers in the component are aligned more markedly in the directional flow. Thus, a possible explanation for the stronger characteristic value decrease in the parallel direction is that the transmission of the fibers to the matrix is inhibited by the substitution of resin with $\mathrm{SMC}$ regrind.

As the results of the tensile strength show no clear influence of the SMC regrind, the values of the elastic modulus are analyzed further. The characteristic values of the elastic modulus measured parallel and transverse to the direction of flow are depicted Figure 10.

parallel $\square$ transverse

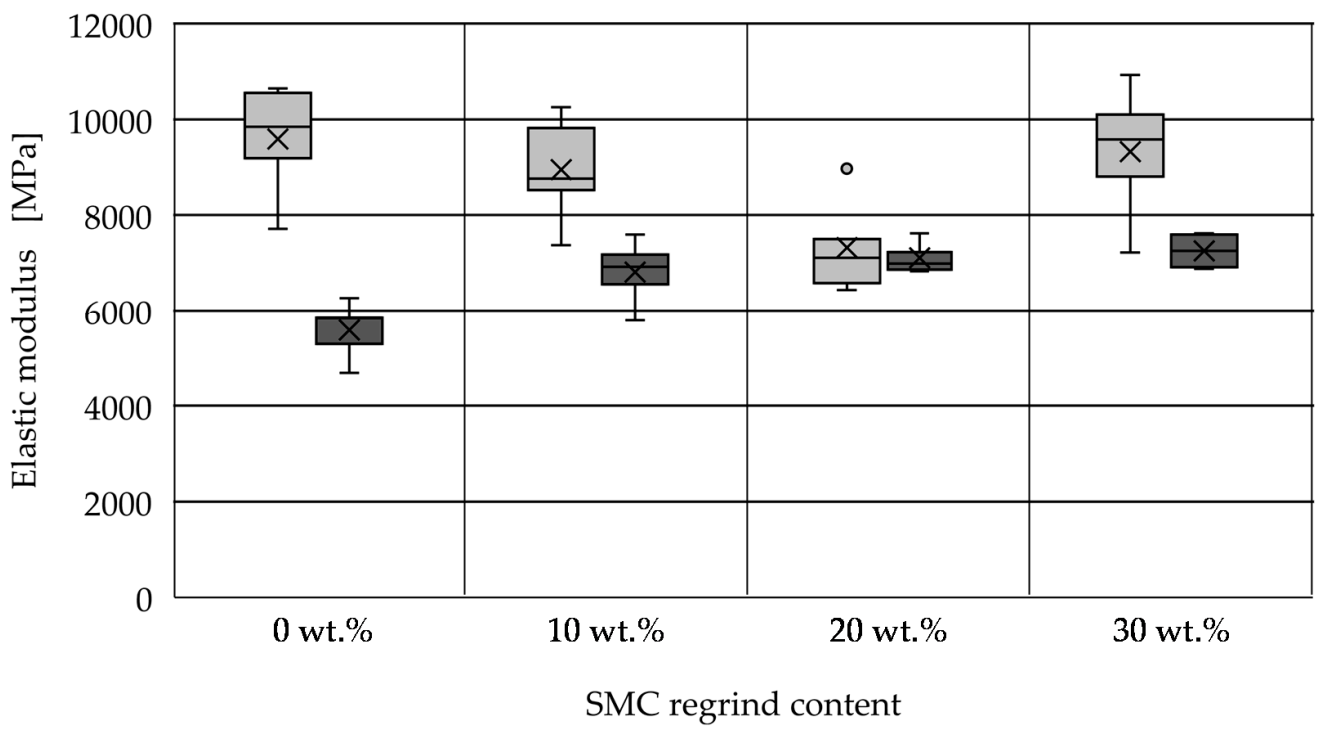

Figure 10. Elastic modulus of SMC components with varied SMC regrind content.

It can be observed that the samples taken in parallel direction show a decreasing elastic modulus. Thus, an increased content of SMC regrind is connected to a reduction in the stiffness of the SMC. In contrast, the SMC components with $\omega_{\mathrm{rSMC}}=30 \mathrm{wt} . \%$ show a similar elastic modulus to the components with $\omega_{\mathrm{rSMC}}=0 \mathrm{wt} . \%$.

The samples taken transverse to the direction of flow also show lower characteristic values than samples taken in parallel direction. Furthermore, the transverse samples show 
a slight increase in the elastic modulus with increasing content of SMC regrind, which indicates that the samples stiffen with increasing levels of recycled material content.

For a closer evaluation, stress-strain curves are depicted in Figure 11. VE-SMC without recyclate content exhibits linear elastic behavior, omitting the degradation of stiffness observed in UP-SMC by OLDENBO ET AL. at strains of 0.003, and which are attributed to onset damage development in the matrix at this point $[25,26]$.
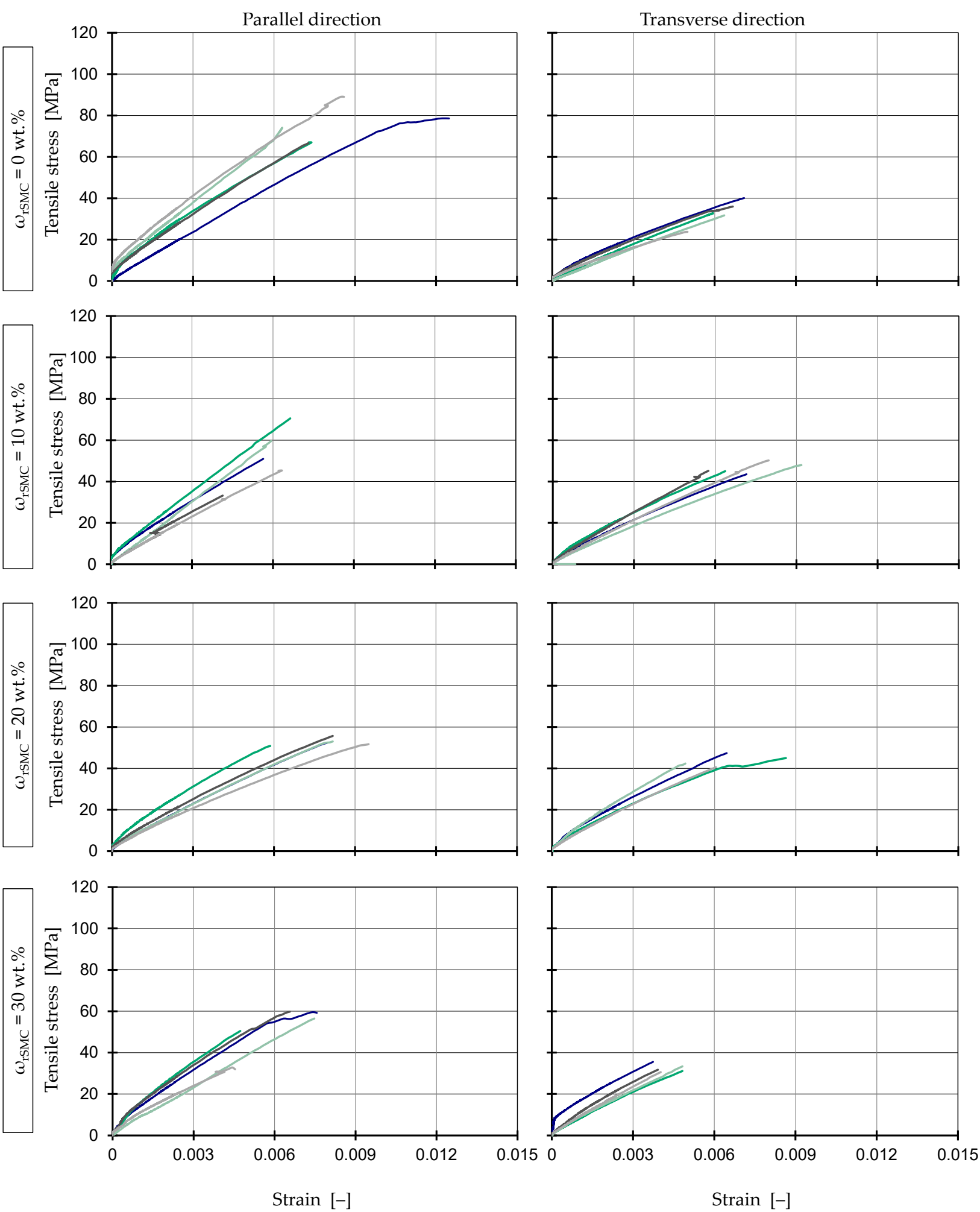

Figure 11. Stress-strain curves of different test specimens for VE-SMC with varying regrind content. 
The addition of the regrind results in the continuous degradation of stiffness with increasing strain levels, which is especially apparent in parallel direction for $\omega_{\mathrm{rSMC}}=20 \mathrm{wt} . \%$ and $\omega_{\mathrm{rSMC}}=30 \mathrm{wt} . \%$. OLDENBO ET AL. attribute this behavior to the continuous formation of multiple micro cracks and increased crack density [26].

The flexural stress measured by means of the bending tests are depicted in Figure 12. When looking at the flexural stress, it is noticeable that the SMC components with $\omega_{\mathrm{rSMC}}=0 \mathrm{wt} . \%$ and $10 \mathrm{wt} . \%$ reach higher breaking stresses than the components with $\omega_{\mathrm{rSMC}}=20 \mathrm{wt} . \%$ and $30 \mathrm{wt} \%$. The SMC with $\omega_{\mathrm{rSMC}}=10 \mathrm{wt} . \%$ demonstrated the highest values, while the SMC with $\omega_{\mathrm{rSMC}}=20 \mathrm{wt} . \%$ shows the lowest values.

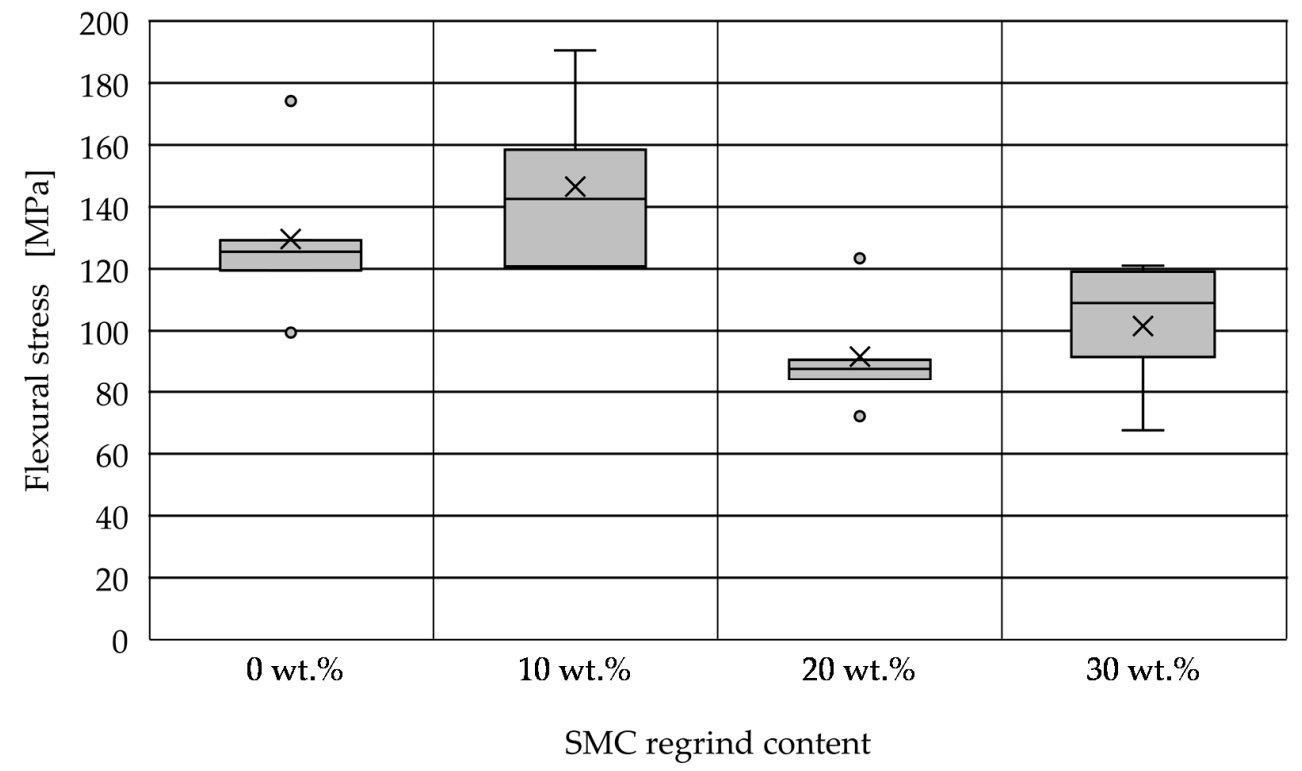

Figure 12. Flexural stress of SMC components with varied SMC regrind content.

The flexural modulus measured by means of the bending test are depicted in Figure 13. With regard to the flexural modulus, a similar trend of the formulations can be observed, however, it was not found to be as pronounced. The SMC components with $\omega_{\mathrm{rSMC}}=10 \mathrm{wt} . \%$ and $30 \mathrm{wt} . \%$ achieve similarly high values. In contrast, the components with $\omega_{\mathrm{rSMC}}=0 \mathrm{wt} . \%$ and $20 \mathrm{wt} . \%$ drop to a similar level.

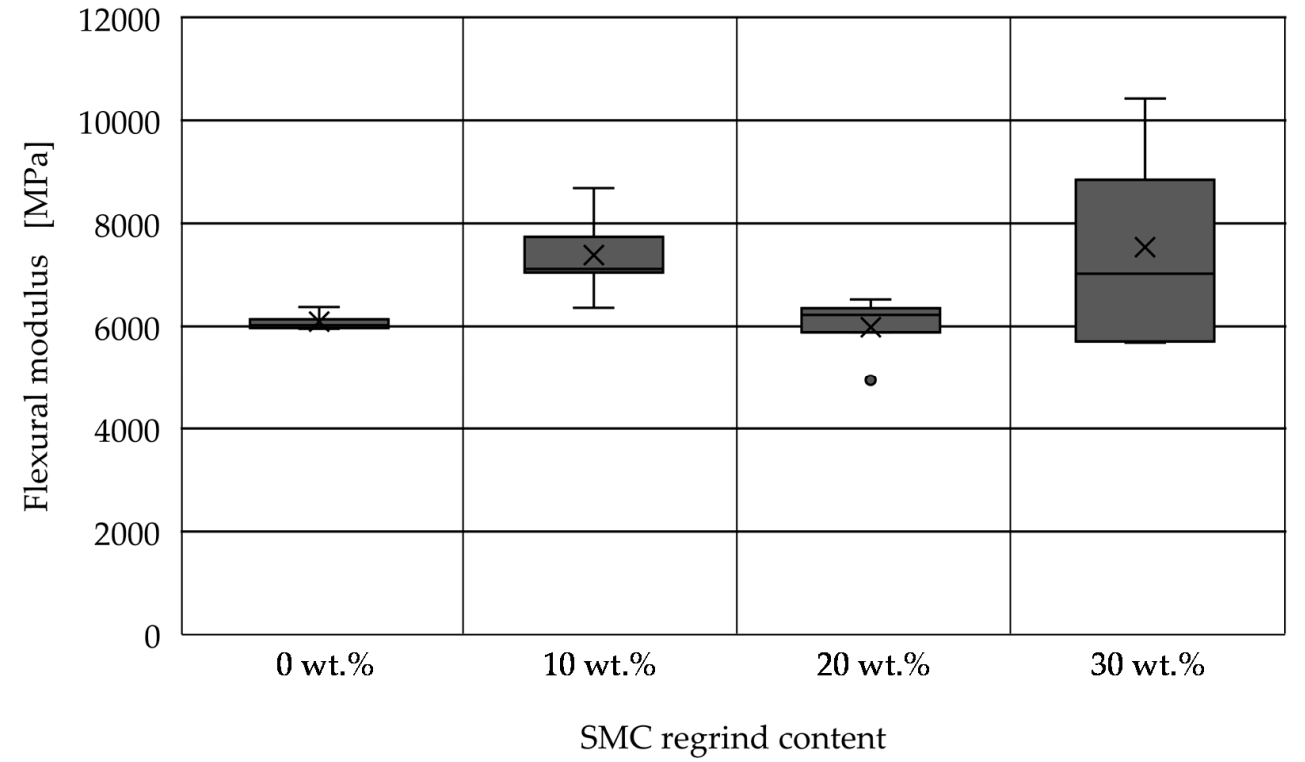

Figure 13. Flexural modulus of SMC components with varied SMC regrind content. 
Both matrix failure and fiber/matrix adhesion failure were observed simultaneously in the mechanical tests. The four-point-bending test specimens mainly fractured due to a tensile-stress induced fracture on the tensile-loaded side of the specimens.

Overall, the elastic and flexural moduli determined in the tensile and bending tests, respectively, show a lower overall dependence on the use of SMC regrind. Furthermore, a slight increase in the characteristic values can even be observed (compare Figures 10 and 13). Substituting the resin with the SMC regrind seems to contribute to an overall increase in the stiffness.

\subsection{Microscopic Characteristics of the SMC Components}

Figure 14 shows micrographs of the cross section over the thickness of the SMC components with varied SMC regrind content. In all micrographs, both fibrous and matrixcontaining areas were observed. A homogeneous distribution over the cross-section is not visible in any sample. However, an inhomogeneity is also to be expected in conventional SMC samples [31]. Moreover, no agglomerates of recycled material were visible in any sample, which can be explained by the use of the dispersion disk and indicates a wellhomogenized matrix.

Pores appear in the micrographs as black areas and can be of different sizes. Small pores can be seen in all recipes and are distributed over the cross section. In the microsection with $\omega_{\mathrm{rSMC}}=30 \mathrm{wt} . \%$, larger pores are visible. Due to the high proportion of recycled material, the basic viscosity of the resin paste increased by almost $40 \%$ (measured by plate plate rheometer following DIN EN ISO 3219), making it more difficult for the paste to vent [39]. The increased number of pores can be used to explain the decreased tensile strength (compare Figure 9) as pores or air inclusions represent a quality-reducing feature [35].

The increase in bending properties with a simultaneous drop in tensile characteristics can be explained by the fact that the matrix properties dominate the bending properties of fiber-reinforced plastics more than the tensile properties. Since the fiber-matrix adhesion became deteriorated by the use of recycled material, this also limited the force transmission of the fibers and thus explains the drop in tensile properties.

The SEM images of SMC components with varied SMC regrind content are depicted in Figure 15. Two selected SEM images are representatively shown for each content of SMC regrind. The initiation of cracks in composites may occur by fiber/matrix debonding, matrix/filler debonding and at fiber ends alike [25,39-41]. In particular, a poor fiber/matrix adhesion can lead to a loss in strength [35,39].

Looking at the image of the SMC component with $\omega_{\mathrm{rSMC}}=0 \mathrm{wt} . \%$, a high amount of matrix remained. It is concluded that a strong adhesion of the matrix to the fibers occurred. The image of the SMC component with $\omega_{\mathrm{rSMC}}=10 \mathrm{wt} . \%$ and $\omega_{\mathrm{rSMC}}=30 \mathrm{wt} . \%$ also show a good adhesion of the matrix. However, some blank fibers are visible, which explains the slightly declining characteristic tensile values in a parallel direction when incorporating SMC regrind.

Additionally, a failure of the matrix component can be seen. The image of the SMC component with $\omega_{\mathrm{rSMC}}=30 \mathrm{wt}$ \% shows a similar fracture pattern to $\omega_{\mathrm{rSMC}}=10 \mathrm{wt} . \%$ with the difference that more blank fibers are visible. Furthermore, it is noticeable that the microsection with $\omega_{\text {rSMC }}=30 \mathrm{wt}$. \% exhibits an increased number of broken-off areas and overall, decreased fiber-matrix adhesion, which causes the decrease of the mechanical properties in parallel direction.

The image of the SMC component with $\omega_{\mathrm{rSMC}}=20 \mathrm{wt}$. $\%$ shows a clearly different fracture pattern as mainly blank fibers are visible. This indicates poor fiber/matrix adhesion and goes along with the deterioration of the mechanical properties of the $\omega_{\mathrm{rSMC}}=20 \mathrm{wt}$. $\%$ components. As the findings do not continue with further increasing of the recyclate content $\left(\omega_{\mathrm{rSMC}}=30 \mathrm{wt} . \%\right)$, a plausible explanation for this effect is the manual manufacturing of the SMC preforms. 


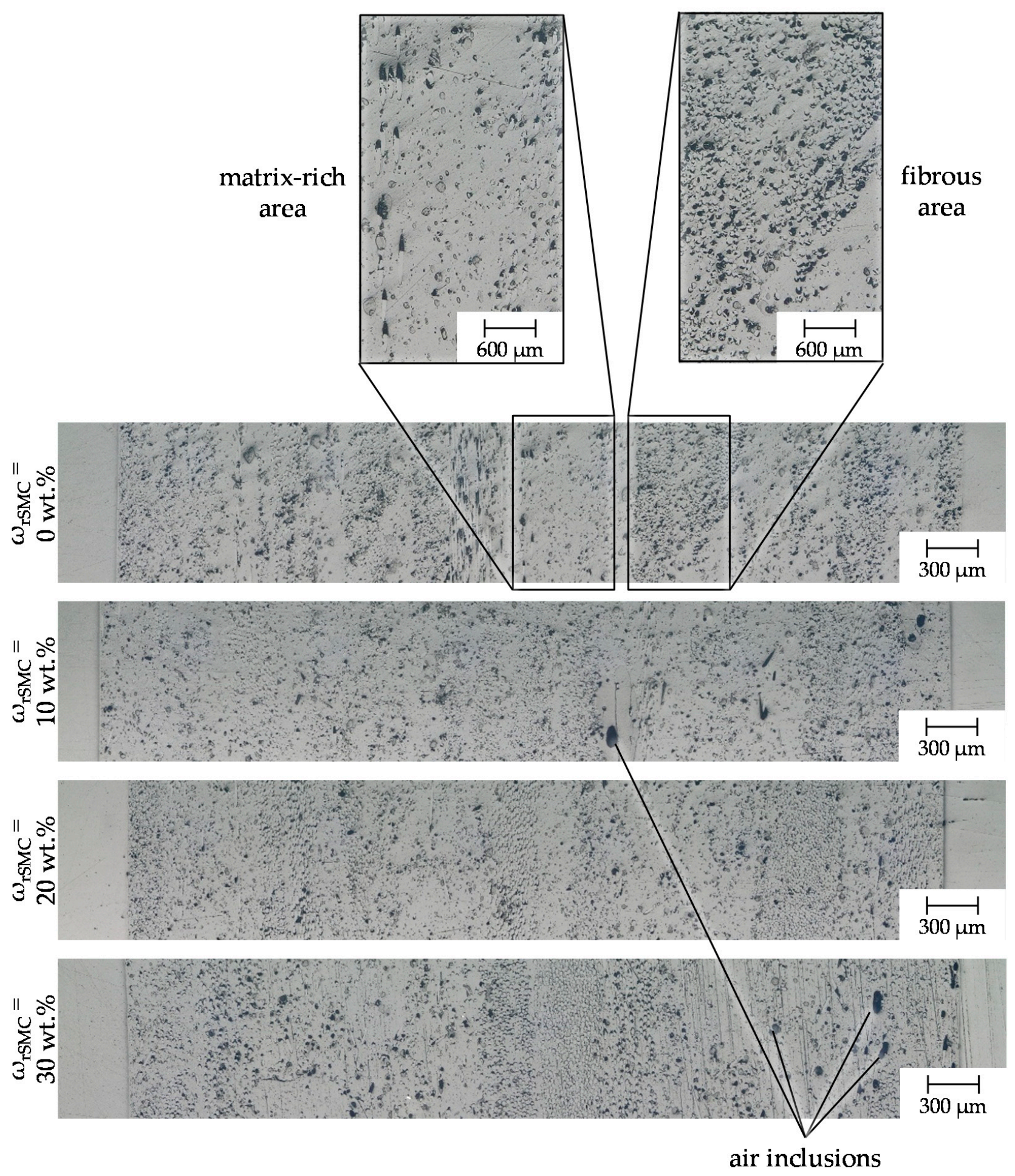

Figure 14. Microsections of SMC components with varied SMC regrind content. 

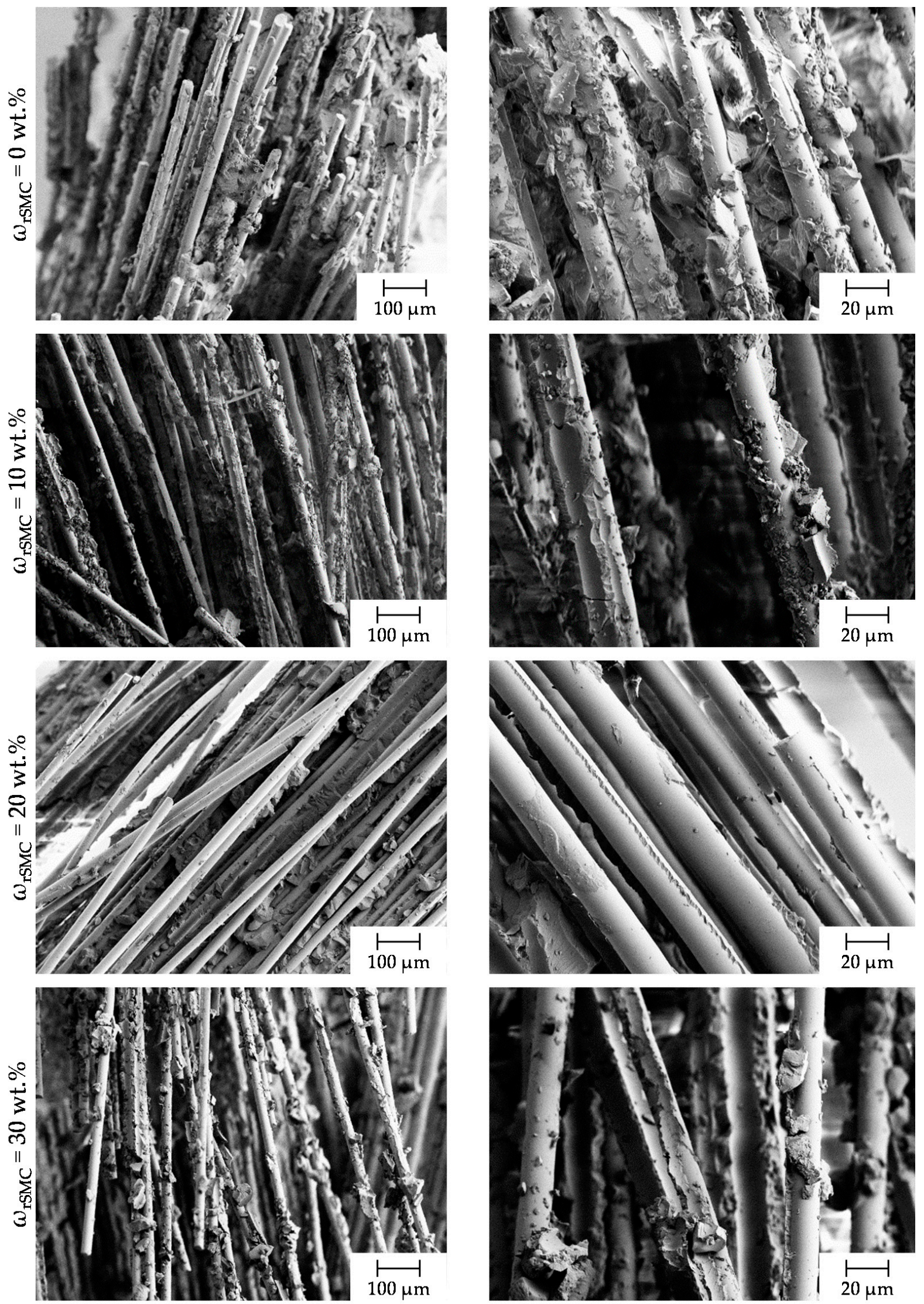

Figure 15. SEM images of SMC components (cryogenic break) with varied SMC regrind content. 


\section{Conclusions}

The mechanical recycling of VE-SMC was investigated in this work and the influence of varied SMC regrind content on the mechanical properties of SMC components was systematically analyzed and evaluated.

The mechanical size deduction of SMC results in a recyclate with fiber- and matrixcontaining fractions with maximum particle sizes of $0.7 \mathrm{~mm}$. The separation into both fractions is not possible due to remaining fiber/matrix adhesion and the significant variation in fiber length.

The manufacturing of the SMC components on a laboratory-scale for this research permitted us to conduct a valid comparative study, since all SMC preforms are manufactured under the same conditions. However, the manual manufacturing of the SMC preforms resulted in increased air inclusions resulting in relatively high standard deviations.

The substitution of the base resin with recycled material leads to a loss in tensile strength, independent of the proportion of recycled material. The average tensile strength was reduced by up to $30 \%$ with the use of recyclate compared to the reference measurements. The reduction in strength does not depend on the proportion of recycled material added and is caused by low fiber/matrix adhesion due to the poor adhesion of the recycled material to the matrix. Furthermore, the increased formation of pores with an increasing proportion of recycled material also has a negative influence on the mechanical properties.

The elastic modulus shows a decreasing tendency as the proportion of recycled material increases, which leads to a reduction in stiffness of the SMC components. The average elastic modulus decreased by up to $23 \%$ with the use of recyclate compared to the reference measurements. The samples taken transversely to the direction of flow, however, show a different trend, and the average elastic modulus could be increased by up to $30 \%$ with the use of recyclate compared with the reference measurements. This indicates flow-induced anisotropic areas within the SMC components plates.

The average flexural stress and flexural modulus can be increased by $13 \%$ and $21 \%$, respectively, by adding $10 \mathrm{wt}$ \% recycled material. However, if the amount of recycled material added is further increased, the bending stress and bending modulus will decrease by up to $29 \%$ compared to the reference measurements. Stress-strain curves of the VE-SMC with recyclate content also show a decrease in stiffness with increasing strain not found in virgin VE-SMC.

Failure mechanisms observed are complex and include both matrix and fiber/matrix adhesion failure of varying dominance. With $\omega_{\mathrm{rSMC}}=10 \mathrm{wt} . \%$ the bending characteristics of the SMC components can be slightly increased. In contrast, the tensile properties decrease with the addition of SMC regrind. However, with an increasing mass percentage of SMC regrind, the tensile properties do not drop significantly further.

Overall, the mechanical recycling of SMC and its reuse in new SMC products has a lot of potential and requires further investigation to develop sustainable and profitable processes. The findings of this work provide a first step towards increasing the resource efficiency of SMC and provides researchers and the end user with reference points as to how much recyclate can be used as a substitute for the resin material without significantly reducing the mechanical properties.

The research on VE-SMC subject to particle recycling should be further promoted in the future. In particular, the influence of an SMC regrind contents greater than $\omega_{\mathrm{rSMC}}=30 \mathrm{wt} . \%$ and regrind-dependent failure mechanisms should be thoroughly investigated further, thus achieving both reliable material properties and high re-use ratios. Furthermore, the decrease in tensile strength with $\omega_{\mathrm{rSMC}} \geq 10 \mathrm{wt} . \%$ can in part be attributed to a reduced fiber-matrix adhesion. Thus, the use of wetting and dispersing additives should be investigated in further studies in order to counteract the increase in processing viscosity due to the use of recycled material resulting in better fiber impregnation.

In addition, a fatigue analysis of SMC containing recyclate should be performed, as the interface between virgin material and recyclate has a decisive influence. Moreover, it is conceivable that the thermodynamics of the materials are influences by means of the 
mechanical recycling and reuse during compression moulding. Thus, differential scanning calorimetry (DSC) investigations could provide further insights into the thermal effects.

Author Contributions: Conceptualization, V.A. and J.N.; methodology, V.A. and J.N.; software, V.A. and J.N.; validation, V.A. and J.N.; formal analysis, V.A., J.N., D.S., R.D. and C.H.; investigation, V.A.; resources, V.A. and J.N.; data curation, V.A. and J.N.; writing-original draft preparation, V.A. and J.N.; writing-review and editing, V.A., J.N., D.S., R.D. and C.H.; visualization, V.A.; supervision, D.S., R.D. and C.H.; project administration, D.S.; funding acquisition, J.N. and D.S. All authors have read and agreed to the published version of the manuscript.

Funding: The investigations set out in this report received financial support from the European Regional Development Fund (No.: EFRE-0801121), to whom we extend our thanks.

Data Availability Statement: The data presented in this study are available on request from the corresponding author.

Acknowledgments: The authors would like to express their gratitude to the Aachen Center for Integrative Lightweight Production (AZL), for the provision of the hydraulic press and the personnel support during the pressing process.

Conflicts of Interest: The authors declare no conflict of interest.

\section{References}

1. Witten, E.; Schuster, A. Der Markt für Glasfaserverstärkte Kunststoffe (GFK) 2019: Marktentwicklungen, Herausforderungen und Chancen; Industrievereinigung Verstärkte Kunststoffe: Frankfurt, Germany, 2019.

2. Witten, E. Aktuelle Entwicklungen und Trends im Composites-Markt. Available online: https://www.weiterbildung.ifam. fraunhofer.de/de/blog/composites-markt.html (accessed on 20 January 2022).

3. Lässig, R.; Eisenhut, M.; Mathias, A.; Schulte, R.T.; Peters, F.; Kühmann, T.; Waldmann, T.; Begemann, W. Serienproduktion von Hochfesten Faserverbundbauteilen: Persprektiven Für Den Deutschen Maschinen- und Anlagenbau; Roland Berger: Munich, Germany, 2012.

4. Stauber, R.C. Kunststoffe und Kunststofftechnologien für das Automobil der Zukunft. ATZextra 2010, 15, 12-17. [CrossRef]

5. Pickering, S.J. Recycling technologies for thermoset composite materials-current status. Compos. Part A Appl. Sci. Manuf. 2006, 37, 1206-1215. [CrossRef]

6. Prinçaud, M.; Aymonier, C.; Loppinet-Serani, A.; Perry, N.; Sonnemann, G. Environmental Feasibility of the Recycling of Carbon Fibers from CFRPs by Solvolysis Using Supercritical Water. ACS Sustain. Chem. Eng. 2014, 2, 1498-1502. [CrossRef]

7. Vo Dong, P.A.; Azzaro-Pantel, C.; Cadene, A.-L. Economic and environmental assessment of recovery and disposal pathways for CFRP waste management. Resour. Conserv. Recycl. 2018, 133, 63-75. [CrossRef]

8. Job, S.; Leek, G.; Mativenga, P.T.; Oliveux, G.; Pickering, S.; Shuaib, N.A. Composites Recycling: Where Are We Now? Composites UK: Berkhamsted, UK, 2016. Available online: https://compositesuk.co.uk/system/files/documents/Recycling\%20Report\%20 2016.pdf (accessed on 20 January 2022).

9. Meng, F.; Pickering, S.J.; McKechnie, J. An Environmental Comparison of Carbon Fibre Composite Waste End-of-life Options. In Proceedings of the SAMPE Europe Conference 2018, Southampton, UK, 11-13 September 2018.

10. Baur, E.; Harsch, G.; Moneke, M. (Eds.) Werkstoff-Führer Kunststoffe: Eigenschaften, Prüfungen, Kennwerte, 11th ed.; Carl Hanser Verlag: Munich, Germany, 2019.

11. Karuppannan Gopalraj, S.; Kärki, T. A review on the recycling of waste carbon fibre/glass fibre-reinforced composites: Fibre recovery, properties and life-cycle analysis. SN Appl. Sci. 2020, 2, 1-21. [CrossRef]

12. Oliveux, G.; Dandy, L.O.; Leeke, G.A. Current status of recycling of fibre reinforced polymers: Review of technologies, reuse and resulting properties. Prog. Mater. Sci. 2015, 72, 61-99. [CrossRef]

13. Ferdous, W.; Manalo, A.; Yu, P.; Salih, C.; Abousnina, R.; Heyer, T.; Schubel, P. Tensile Fatigue Behavior of Polyester and Vinyl Ester Based GFRP Laminates-A Comparative Evaluation. Polymers 2021, 13, 386. [CrossRef]

14. Ferdous, W.; Ngo, T.D.; Nguyen, K.T.Q.; Ghazlan, A.; Mendis, P.; Manalo, A. Effect of fire-retardant ceram powder on the properties of phenolic-based GFRP composites. Compos. Part B Eng. 2018, 155, 414-424. [CrossRef]

15. Reygrobellet, J.N.; Lopez Cuesta, J.M.; Crespy, A. Incorporation of unsaturated polyester based matrix composites into a PP-PE copolymer for recycling. In International Committee on Composite Materials, Proceedings of the 1999 International Conference on Composite Materials, Paris, France, 5-9 July 1999; ICCM/12TCA: Tours, France, 2000.

16. Winter, H.; Mostert, H.A.M.; Smeets, P.J.H.M.; Paas, G. Recycling of sheet-molding compounds by chemical routes. J. Appl. Polym. Sci. 1995, 57, 1409-1417. [CrossRef]

17. Tesoro, G.; Wu, Y. Chemical Products from Cured Unsaturated Polyester. Adv. Polym. Technol. 1993, 12, 185-196. [CrossRef]

18. Henshaw, J.M.; Han, W.; Owens, A.D. An Overview of Recycling Issues for Composite Materials. J. Thermoplast. Compos. Mater. 1996, 9, 4-20. [CrossRef] 
19. Derosa, R.; Telfeyan, E.; Mayes, J.S. Current State of Recycling Sheet Molding Compounds and Related Materials. J. Thermoplast. Compos. Mater. 2005, 18, 219-240. [CrossRef]

20. Petterson, J.; Nilsson, P. Recycling of SMC and BMC in Standard Process Equipment. J. Thermoplast. Compos. Mater. 1994, 7, 56-63. [CrossRef]

21. Inoh, T.; Yokoi, T.; Sekiyama, K.-I.; Kawamura, N.; Mishima, Y. SMC Recycling Technology. J. Thermoplast. Compos. Mater. 1994, 7, 42-55. [CrossRef]

22. Seiler, E.; Teipel, U. Recycling von Kompositbauteilen aus Kunststoffen als Matrixmaterial—ReKomp Abschlussbericht Projektverbund ForCycle-Ressourcenstrategie für Bayern unter Besonderer Berücksichtigung von Sekundärrohstoffen, Nürnberg. 2017. Available online: https:/ / docplayer.org/56978897-Abschlussbericht-recycling-von-kompositbauteilen-aus-kunststoffenals-matrixmaterial-rekomp-laufzeit.html (accessed on 20 January 2022).

23. Fette, M.; Hentschel, M.; Santafe, J.G.; Wille, T.; Büttemeyer, H.; Schiebel, P. New Methods for Computing and Developing Hybrid Sheet Molding Compound Structures for Aviation Industry. Procedia CIRP 2017, 66, 45-50. [CrossRef]

24. Oldenbo, M.; Fernberg, S.P.; Berglund, L.A. Mechanical behaviour of SMC composites with toughening and low density additives. Compos. Part A Appl. Sci. Manuf. 2003, 34, 875-885. [CrossRef]

25. Oldenbo, M. Anisotropy and Non-Linear Effects in SMC Composites: From Material Data to FE-Simulation of Structures Ph.D. Thesis, Luleå University of Technology, Luleå, Sweden, 2004.

26. Palmer, J.; Ghita, O.R.; Savage, L.; Evans, K.E. Recyclate fibres-matrix interface analysis for reuse in sheet moulding compounds (SMC). In Proceedings of the 13th European Conference on Composite Materials, Stockholm, Sweden, 2-5 June 2008.

27. Gortner, F. Bio-Basierte und Nachwachsende Füllstoffe für Dichtereduzierte Sheet Molding Compounds. Ph.D. Thesis, Technische Universität Kaiserslautern, Kaiserslautern, Germany, 2019.

28. Kia, H.G. (Ed.) Sheet Moulding Compounds: Science and Technology; Hanser Gardner Publications: Cincinnati, OH, USA; Munich, Germany, 1993.

29. Orgéas, L.; Dumont, P.J.J. Sheet Moulding Compounds. In Wiley Encyclopedia of Composites; Nicolais, L., Borzacchiello, A., Lee, S.M., Eds.; Wiley Interscience: Hoboken, NY, USA, 2011.

30. Kim, D.-H.; Kim, H.-G.; Kim, H.-S. Design optimization and manufacture of hybrid glass/carbon fiber reinforced composite bumper beam for automobile vehicle. Compos. Struct. 2015, 131, 742-752. [CrossRef]

31. Sambale, H. Fiber Spraying Process for Efficient Preform Production. Available online: https://en.kunststoffe.de/a/article/ article-276444 (accessed on 20 January 2022).

32. Schmidt \& Heinzmann GmbH \& Co. KG. Fiber Spraying. Available online: https://schmidt-heinzmann.de/fiber-processing/ fiber-spraying/ (accessed on 20 January 2022).

33. Keckl, C. Einfluss der Eindickung von Dichtereduziertem Sheet Moulding Compound auf Die Formteilwelligkeit. Ph.D. Thesis, Karlsruher Institut für Technologie, Karlsruhe, Germany, 2016.

34. Macherauch, E.; Zoch, H.-W. Praktikum in Werkstoffkunde: 95 Ausführliche Versuche aus Wichtigen Gebieten der Werkstofftechnik, 12th ed.; Springer Vieweg: Wiesbaden, Germany, 2014.

35. Erdmann, J. Biobasierte Kunststoffe mit Cellulosefaserverstärkung: Zusammenhänge Zwischen Struktur, Haftung und Mechanischen Eigenschaften. Ph.D. Thesis, Martin-Luther-Universität Halle-Wittenberg, Halle, Germany, 2017.

36. Lamanna, G.; Ceparano, A. Mechanical Characterization of Sheet Moulding Composites for the Automotive Industry. Open Mater. Sci. 2014, 8, 108-113. [CrossRef]

37. Piry, M. Mechanische Auslegung von SMC-Bauteilen und Charakterisierung der Relevanten Werkstoffeigenschaften: Mechanical Dimensioning of SMC-Components and Characterization of the Relevant Material Properties. Ph.D. Thesis, RheinischWestfälische Technische Hochschule Aachen, Aachen, Germany, 2004.

38. Schiebisch, J. Zum Recycling von Faserverbundkunststoffen mit Duroplastmatrix. Ph.D. Thesis, Universität Erlangen-Nürnberg, Erlangen, Germany, 1995.

39. Hour, K.-Y.; Sehitoglu, H. Damage Development in a Short Fiber Reinforced Composite. J. Compos. Mater. 1993, $27,782-805$. [CrossRef]

40. Wang, S.S.; Chim, E.-M. Fatigue Damage and Degradation in Random Short-Fiber SMC Composite. J. Compos. Mater. 1983, 17, 114-134. [CrossRef]

41. Fitoussi, J.; Guo, G.; Baptiste, D. A statistical micromechanical model of anisotropic damage for S.M.C. composites. Compos. Sci. Technol. 1998, 58, 759-763. [CrossRef] 